\title{
Analysis of the Resonator Element in Different Positions in the Circular Patch Microstrip Antenna
}

\author{
Adelson Menezes Lima ${ }^{1,2}$ (D), João Victor de Freitas ${ }^{2}$ (D), Otávio Paulino Lavor ${ }^{2}$ (]) \\ ${ }^{I}$ Electrical Engineering Department, Federal University of Rio Grande do Norte/UFRN, Natal, Brazil. \\ adelsonmlima@gmail.com \\ ${ }^{2}$ Technology and Engineering Department, Federal Rural University of the Semi-Arid Region/UFERSA, Pau \\ dos Ferros, Brazil \\ joaovictor_freitas@hotmail.com,otavio.lavor@ufersa.edu.br
}

\begin{abstract}
In this article, a circular patch microstrip antenna with a metamaterial resonator for $\mathbf{4 G}$ applications is proposed. For the design of the circular antenna patch, an approximate calculation was performed. The circular resonator is inserted into the patch for some antennas, in different positions for a parametric study. When incorporating the resonator, the performance of the antenna is improved and analyzed through some parameters, when compared with the antenna without the resonator. To verify the influence of the resonator and validate its performance, simulated results were performed with the ANSYS HFSS ${ }^{\circledR}$ software and compared with the experimental results, through prototypes, in which they showed a good agreement.
\end{abstract}

Index Terms - Antenna design, patch, metamaterial, CSRR, gain.

\section{INTRODUCTION}

Microstrip antennas in the field of wireless communication systems, require attractive features and properties, such as thin surface, light weight, easy to manufacture and to integrate with existing communication devices [1]. With the recent technological advances, these combined characteristics of artificial materials become important to contribute in antennas miniaturization and performance.

Given this context, over several years, several techniques and ways to build the antennas were recommended to improve their performance, as it is directly related to certain parameters, such as, for example, patch geometry, electrical permittivity, magnetic permeability of the substrate and ground plane of the microstrip antenna [1]. One of the techniques proposed for antenna projects and of great interest to researchers, is the use of metamaterials (MTMs). The use of MTMs reduces the size of the antenna, but it can also improve other parameters, such as increased bandwidth (BW), gain, radiation diagram, multiband frequencies of operation, in addition to contributing to the application of sensors, reducing absorption electromagnetic, as well as harmonic filter [2] - [6].

Metamaterial (MTM) is a material structure that has alternative permittivity $(\varepsilon)$ and permeability $(\mu)$, which is difficult to find in nature. Due to Veselago research in 1968, which proposed the propagation of electromagnetic waves in artificial material [7] on the existence of substances with $\varepsilon$ and $\mu$ simultaneously negative, MTMs structures started to be applied in the construction of microstrip 
antennas, and inserted in the patch, substrate and ground plane [2] - [8].

In the literature, some resonator models are studied for applications in microstrip antennas, such as Split Ring Resonator (SRR), Complementary Split Ring Resonator (CSRR), High Impedance Surfaces (HIS), the Left-Handed Metamaterial (LHM), and a single Capacitive-Loaded Split Rectangular Loop (CLL) [2] - [11].

In addition, some works report antenna designs with resonant MTM geometries immersed in the microstrip antenna patch, as in [4], who investigated an MTM based on Hilbert's fractal geometry, manufactured with printing of conductive material on the substrate. Increased bandwidth on two frequencies and increased gain. For [6], who proposed an MTM CSRR resonator for a UWB antenna that wishes to reject a frequency band. According to [7], an active MTM CSRR ring structure, based on varicap diodes, obtaining multibands. In [8], an X band antenna with circular SRR slots to achieve narrow bandwidth was designed. For [12], it was designed an antenna with a CSRR resonator and proposed two techniques. The first is made up of a split ring resonator cell. In the second, an arrangement of split periodic resonators was integrated. In both techniques, the resonators had variable positions and angles in order to find the best results. In [13], an antenna with a CSRR resonator is designed and used as a sensor, which can be applied to characterize different types of dielectric materials, in addition to being used to determine the percentage of water contained in different types of soil. In [14], it was proposed a Rectangular MTM Complementary Split Ring Resonator (RCSRR), contributing to the antenna miniaturization, good impedance matching, gain and bandwidth. For [15], split SRR square rings were used next to the antenna patch with PIN diodes. Control in the direction of the beam was investigated, obtaining a better gain and bandwidth for a frequency. In [16], an antenna with an MTM matrix in Hexagonal Complementary Split Ring Resonators (CSRRs) was used to evaluate the frequency response and radiation performance of the antenna. Another article developed a circular CSRR for broadband applications with reduced antenna size [17]. Finally, a design of a compact Multiple Split Ring Resonator (MSRR) obtained a better frequency, compact antenna for wireless local area network (WLAN) and radio frequency identification (RFID) applications [18].

Thus, in this work an MTM CSRR resonator for $2.6 \mathrm{GHz}$ is proposed and analyzed in different positions in microstrip patch antenna. In addition, an approximate calculation for the size of the circular patch is applied. Electromagnetic simulations were performed using the ANSYS HFSS ${ }^{\circledR}$ software. The simulated and experimental results were investigated through the parameters of return loss (RL), bandwidth (BW), radiation diagram, gain, Smith chart graphic and current distribution.

\section{CSRR DESIGN}

The MTM structure called Complementary Split Ring Resonator (CSRR) was proposed by Pendry based on SRR geometry, these two geometries being the most explored by researchers, since they have resonant elements and provide a high quality factor in the frequencies of microwaves and 
millimeter waves [6], [19] - [20]. With the advancement of SRR and CSRR, other forms of geometries have emerged, such as square and triangular. The geometries are formed by two concentric rings with divisions in their opposite in the inner and outer rings, having behavior characteristics such as, stop band device, electric dipole and negative effective permeability [6], [21].

CSRR is produced by etching ring-shaped grooves on the metallic part of the upper or lower surface of microstrip antena substrate, and its electrical and magnetic properties are exchanged in relation to the SRR. In addition, it can be excited by a time-varying axial electric field and exhibit negative values of dielectric permittivity [21]. Fig. 1a shows the comparison between an SRR and CSSR geometry, while Fig. 1b shows the CSRR equivalent circuit [21].

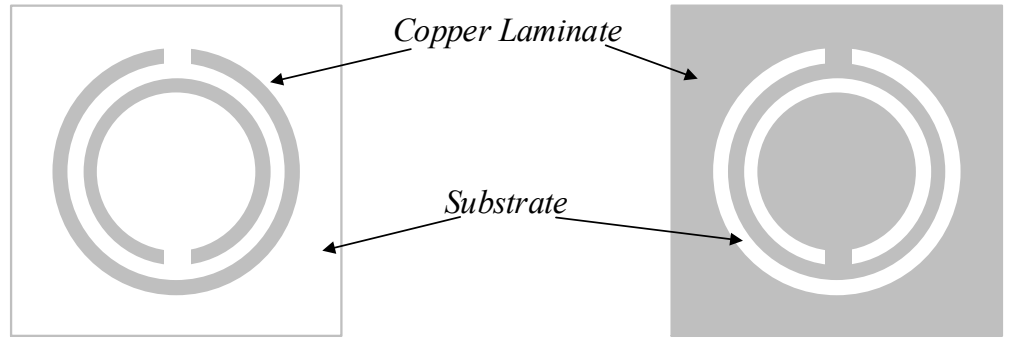

(a)

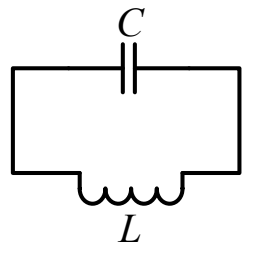

(b)

Fig. 1. (a) SRR and CSRR, b) Electric equivalent circuit.

As the geometry works according to an equivalent circuit, the resonance frequency can be determined by (1) [6], [19] - [20].

$$
\omega_{0}=\sqrt{\frac{2}{\Pi r L C}}
$$

where $\omega_{0}$ is the resonance frequency, $L$ is the inductance per length, $C$ is the total capacitance of the CSRR and $r$ is the average radius of two annular slots.

Based on the MTM CSRR geometry presented in the literature, the resonator for this work was designed and defined empirically by means of computer simulations, until obtaining a good agreement with the microstrip antenna patch design. Thus, the geometry was shown in Fig. 2. The dimensions were called $r_{0}=1.6 \mathrm{~mm}, r_{1}=2.8 \mathrm{~mm}, r_{2}=4 \mathrm{~mm}$ and $r_{3}=5.2 \mathrm{~mm}$.

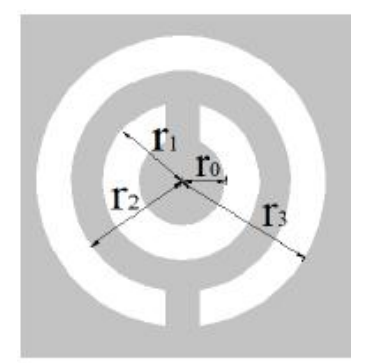

Fig. 2. Proposed CSRR.

\section{AntenNa Designs AND Resonator Positions}

The antennas were designed for $4 \mathrm{G}$ applications with $2.6 \mathrm{GHz}$, considered an input impedance of $50 \Omega$ and excited from a power line with a quarter of the wavelength. The material adopted in the patch, transmission line and ground plane, was copper laminate with a thickness of $0.05 \mathrm{~mm}$. For the 
dielectric substrate, FR4 (Fiberglass) with a thickness of $1.58 \mathrm{~mm}$ was adopted, which is normally applied to wireless devices and has a dielectric constant $\varepsilon_{r}=4.4$ with a loss tangent $(\delta)$ equal to 0.02 .

\section{A. Antenna without Resonator}

In the antenna without resonator, its design was considered the use of inset fed for better power transfer and impedance matching. To determine the dimensions of the microstrip antenna, normally the literature presents studies with the rectangular patch [1], [22]. It is worth mentioning that the most used method for calculating the values of $W g$ and $L g$, is the method of the transmission line [1]. In this work, an approximation calculation to determine the dimensions of the circular antenna patch (Fig. 3), was considered by equation (2) [23]. The antenna dimensions are shown in Table I.

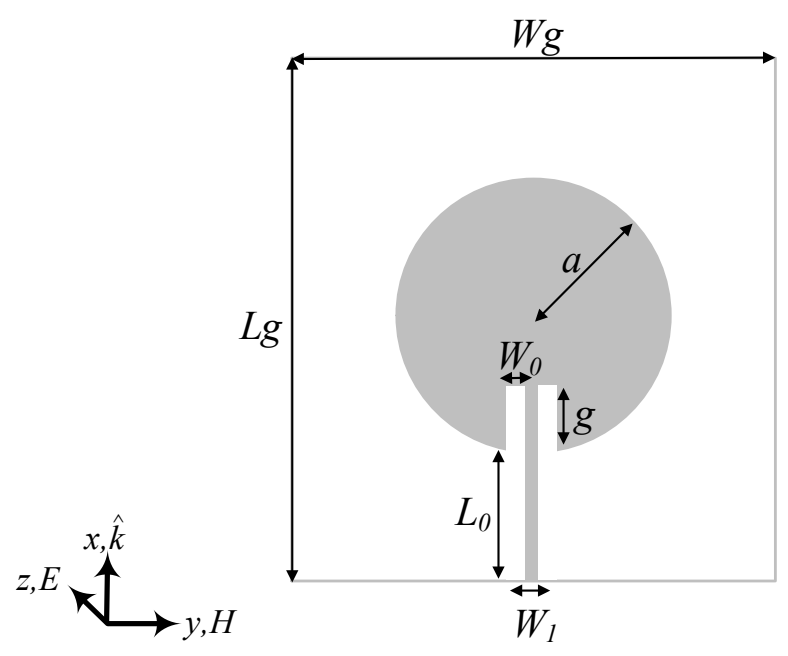

Fig. 3. Antenna with circular patch.

$$
a=\frac{W g+L g}{4}
$$

TABLE I. ANTENNA DIMENSIONS

\begin{tabular}{cc}
\hline Parameters & Values $(\mathbf{m m})$ \\
\hline Feed line $\left(L_{0}\right)$ & 13 \\
\hline Ground length $(\mathrm{Lg})$ & 46 \\
\hline Ground width $(\mathrm{Wg})$ & 40 \\
\hline Inset fed $(g)$ & 16 \\
\hline Inset gap $\left(W_{0}\right)$ & 1.82 \\
\hline Line width $\left(W_{l}\right)$ & 1.58 \\
\hline Radius $(a)$ & 16.15 \\
\hline
\end{tabular}

\section{B. Antennas with Resonator}

From the antenna without resonator, the antenna with resonator was proposed without an inset fed, keeping the same dimensions of the antenna, to analyze the influence of the resonator on the performance of the antenna. Then the MTM CSRR was inserted into the antenna patch for four 
proposals. For each antenna, the position of the CSRR was defined as position A, B, C and D, as shown in Fig. 4. The positions were determined from the coordinate systems placed in the center of the patch. Thus, the positions are determined by the semi-axes. Each position of the resonator in the antenna patch, obeys distances that are shown in Table II.

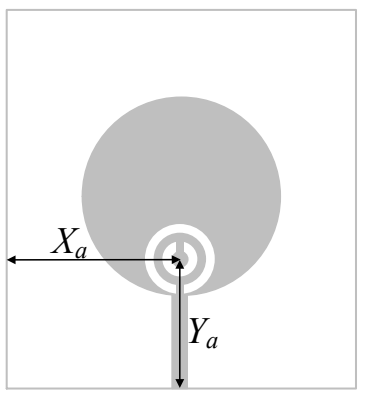

(a)

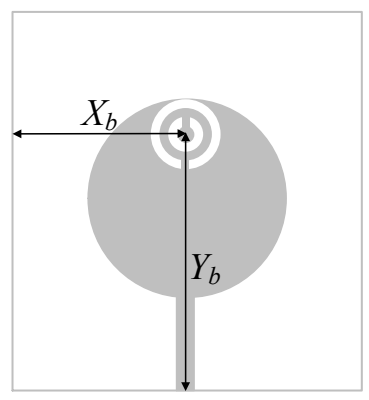

(b)

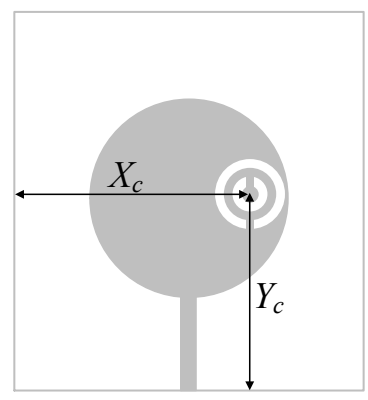

(c)

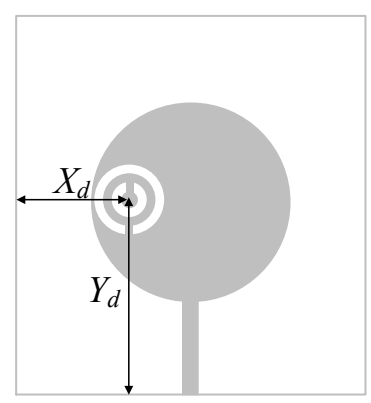

(d)

Fig. 4. Resonator antenas a) Position A, b) Position B, c) Position C, d) Position D.

TABLE II. DISTANCES OF THE RESONATOR POSITION IN THE ANTENNA PATCH.

\begin{tabular}{cccccccccc}
\hline \multirow{2}{*}{ Parameters } & \multicolumn{3}{c}{ Position A } & \multicolumn{2}{c}{ Position B } & \multicolumn{2}{c}{ Position C } & \multicolumn{2}{c}{ Position D } \\
\cline { 2 - 10 } & $\mathrm{Xa}$ & $\mathrm{Ya}$ & $\mathrm{Xb}$ & $\mathrm{Yb}$ & $\mathrm{Xc}$ & $\mathrm{Yc}$ & $\mathrm{Xd}$ & $\mathrm{Yd}$ \\
\hline Distance (mm) & 20 & 17.9 & 20 & 38 & 30 & 27.95 & 10 & 27.95 \\
\hline
\end{tabular}

\section{RESUlts AND Discussions}

In this section, we present the results of the simulations and measurements from the prototypes of Fig. 5, in order to validate the antenna without resonator and the proposed antennas with resonator. The simulations were performed using the ANSYS HFSS ${ }^{\circledR}$ software, and the measurements were performed by a vector network analyzed (VNA). The graphics were simulated using open source Scilab software.

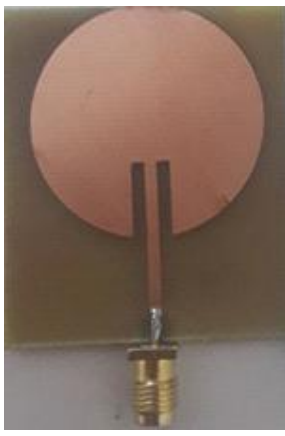

(a)

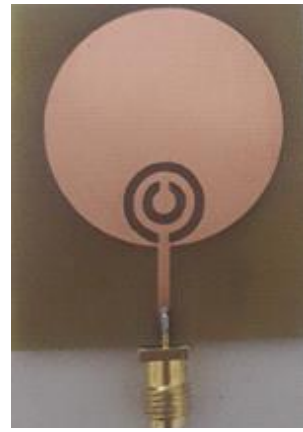

(b)

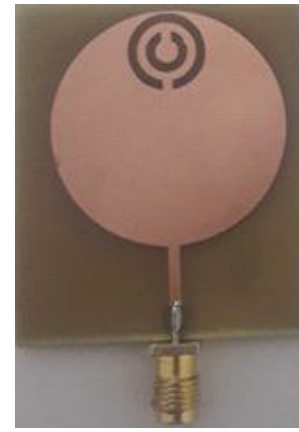

(c)

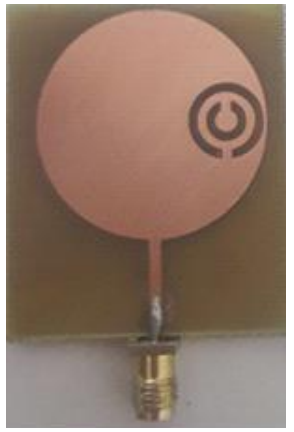

(d)

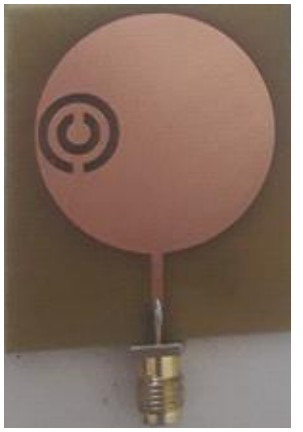

(e)

Fig. 5. Antenas prototypes a) Without resonator, b) Position A, c) Position B, d) Position C, e) Position D.

For the antenna without resonator (Fig. 5a), a frequency of $2.62 \mathrm{GHz}$ and RL of $-15.5 \mathrm{~dB}$ (Fig. 6) are observed in the simulated result. For the measured result, it presents the frequencies of $2.25 \mathrm{GHz}$, $2.75 \mathrm{GHz}$ and $\mathrm{RL}$ of $-12.5 \mathrm{~dB},-22.5 \mathrm{~dB}$. Fig. 7 shows the plane $\mathrm{E}$ and $\mathrm{H}$ of the radiation diagram and the gain. For the antenna with resonator in position A (Fig. 5b), Fig. 8 presents in the simulation a 
frequency of $2.12 \mathrm{GHz}$ and RL of $-6.26 \mathrm{~dB}$. For measurement, it has a frequency of $2.25 \mathrm{GHz}$ and an $\mathrm{RL}$ of $-20.65 \mathrm{~dB}$. It is observed that with the presence of the resonator, filtering occurs in more modes when compared to Fig. 6 of the antenna without resonator. In addition, both results show results with close frequencies. Fig. 9 shows the plane $\mathrm{E}$ and $\mathrm{H}$ of the radiation diagram and the gain.

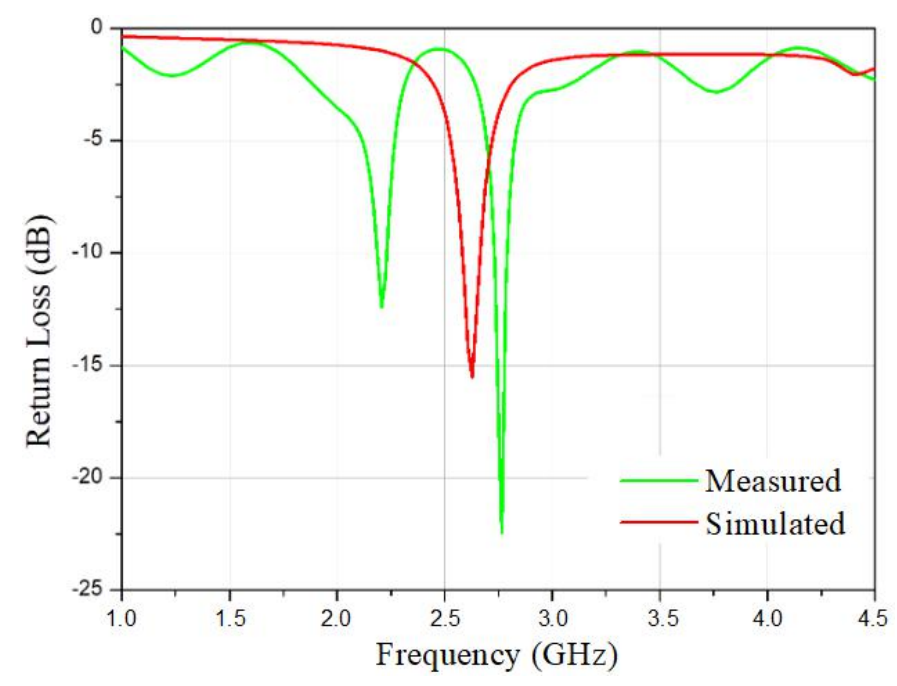

Fig. 6. Return loss to the antenna without resonator.

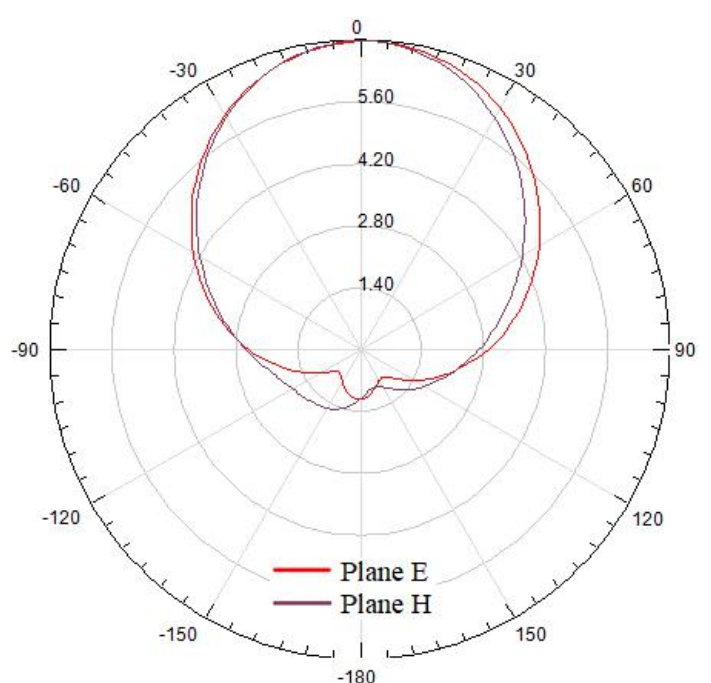

(a)

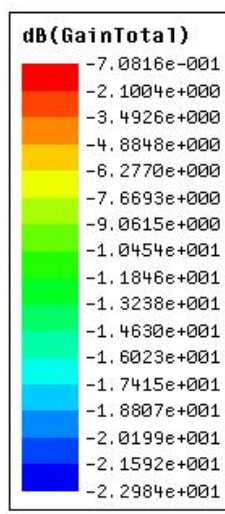

(b)

Fig. 7. Radiation and gain diagram a) 2D, b) 3D. 


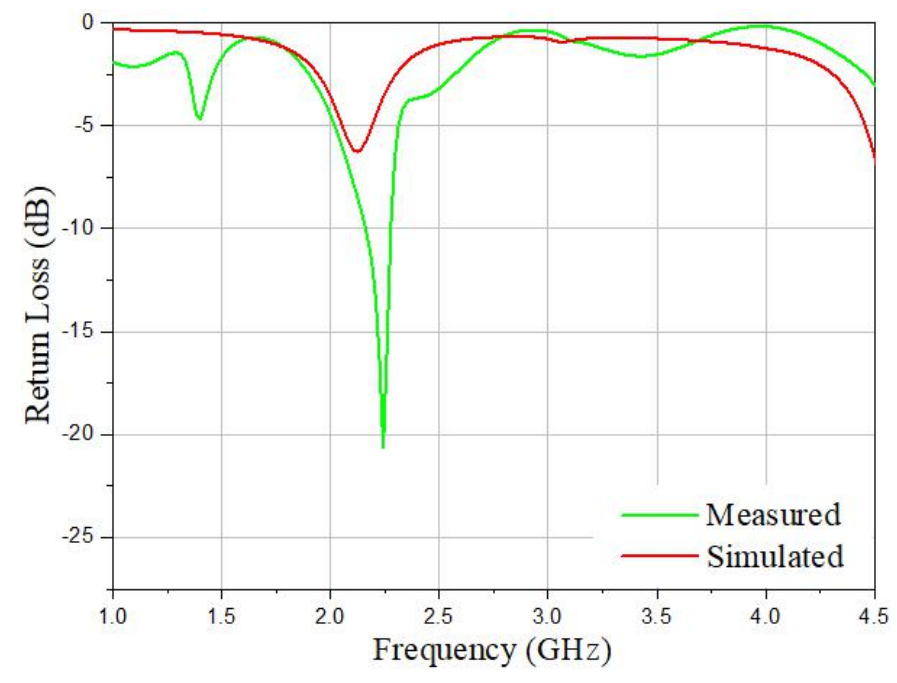

Fig. 8. Return loss to position A.

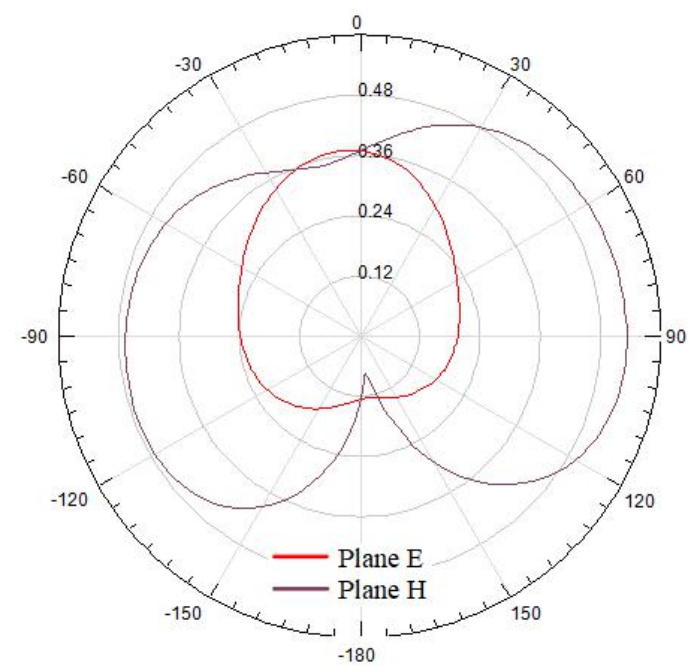

(a)

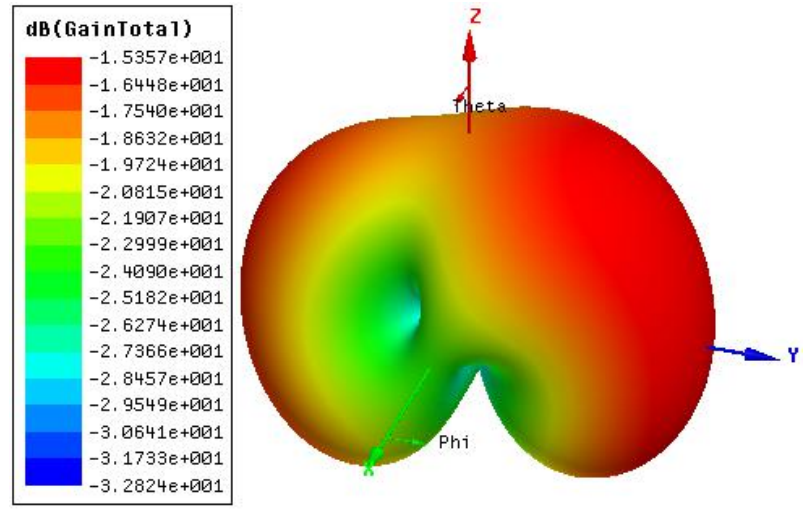

(b)

Fig. 9. Radiation and gain diagram a) 2D, b) 3D.

For the antenna with resonator in position B (Fig. 5c), Fig. 10 presents in the simulation the frequencies of $2.49 \mathrm{GHz}, 2.9 \mathrm{GHz}, 4.45 \mathrm{GHz}$ and $\mathrm{RL}$ of $-24.82 \mathrm{~dB},-17.26 \mathrm{~dB},-6.83 \mathrm{~dB}$. For measurement, they have frequencies of $2.22 \mathrm{GHz}, 2.54 \mathrm{GHz}, 2.96 \mathrm{GHz}$ and $\mathrm{RL}$ of $-10.84 \mathrm{~dB},-8.75$ $\mathrm{dB},-16.42 \mathrm{~dB}$. In addition, both results show close results and good agreement. Fig. 11 shows the plane $\mathrm{E}$ and $\mathrm{H}$ of the radiation diagram and the gain. 


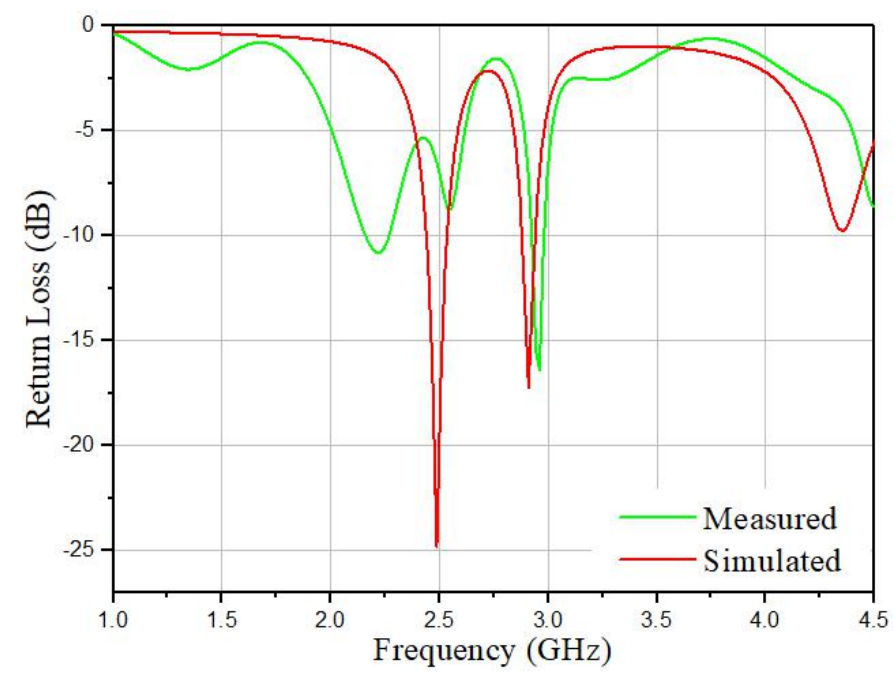

Fig. 10. Return loss to position B.

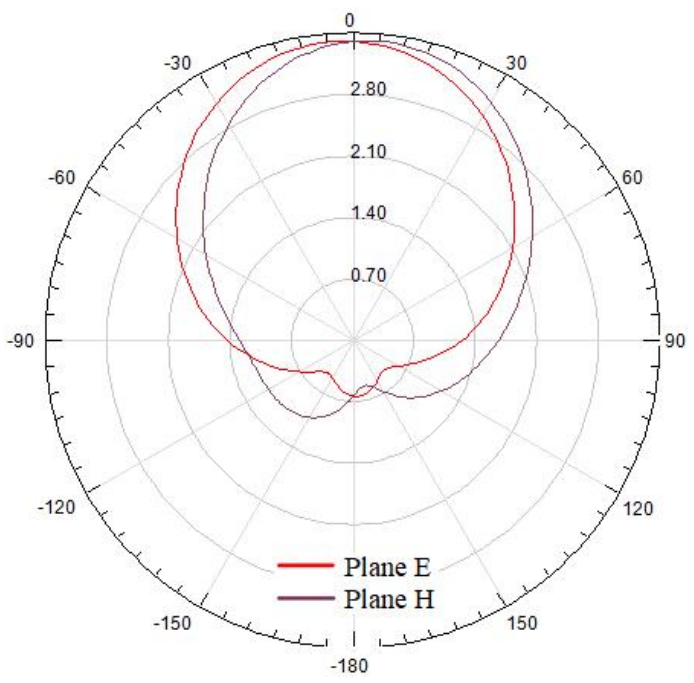

(a)

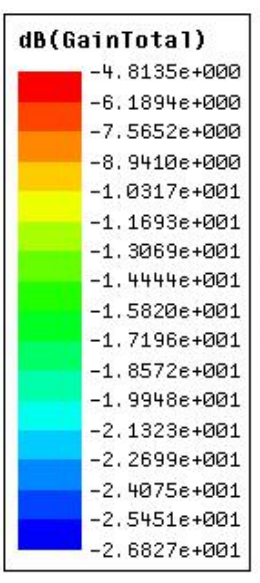

(b)

Fig. 11. Radiation and gain diagram a) 2D, b) 3D.

For the antenna with resonator in position $\mathrm{C}$ (Fig. 5d), Fig. 12 shows in the simulation the frequencies of $2.18 \mathrm{GHz}, 2.5 \mathrm{GHz}, 3.21 \mathrm{GHz}, 4.48 \mathrm{GHz}$ and $\mathrm{RL}$ of $-7.57 \mathrm{~dB},-19.94 \mathrm{~dB},-16.76 \mathrm{~dB}$, $18.34 \mathrm{~dB}$. For measurement, they have the frequencies of $2.26 \mathrm{GHz}, 2.55 \mathrm{GHz}, 3.19 \mathrm{GHz}$ and RL of $8.32 \mathrm{~dB},-10.55 \mathrm{~dB},-24.17 \mathrm{~dB}$. In addition, both results show close results with good agreement. Fig. 13 shows the $\mathrm{E}$ and $\mathrm{H}$ plane of the radiation diagram and the gain. 


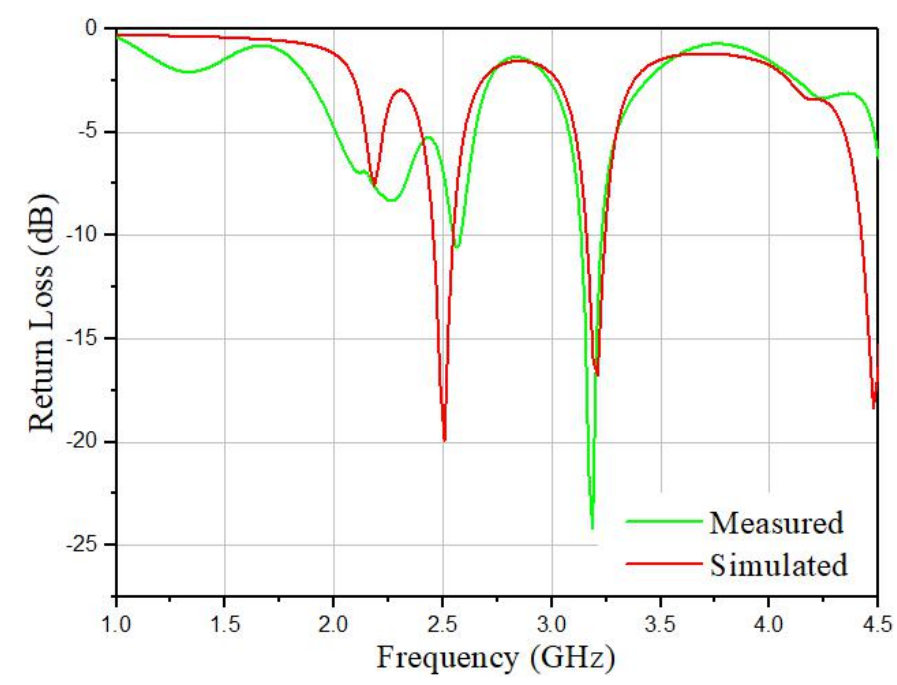

Fig. 12. Return loss to position C.

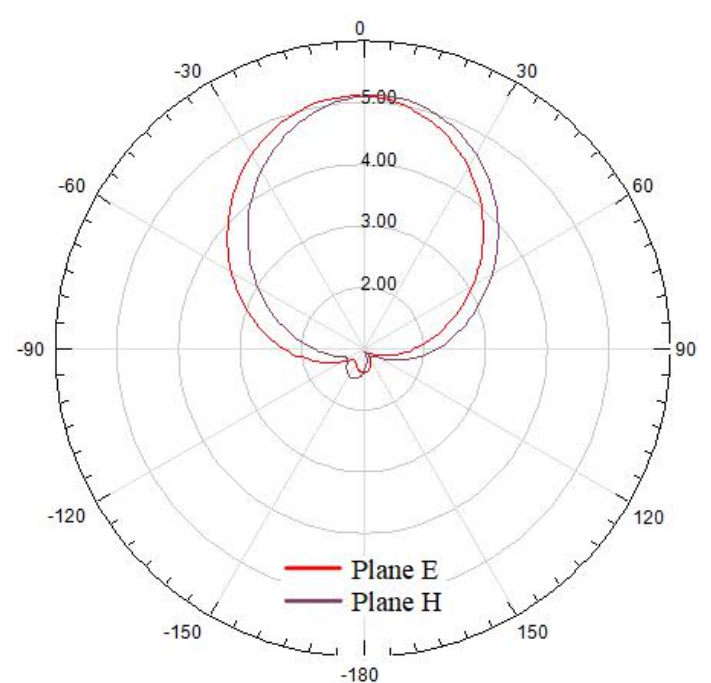

(a)

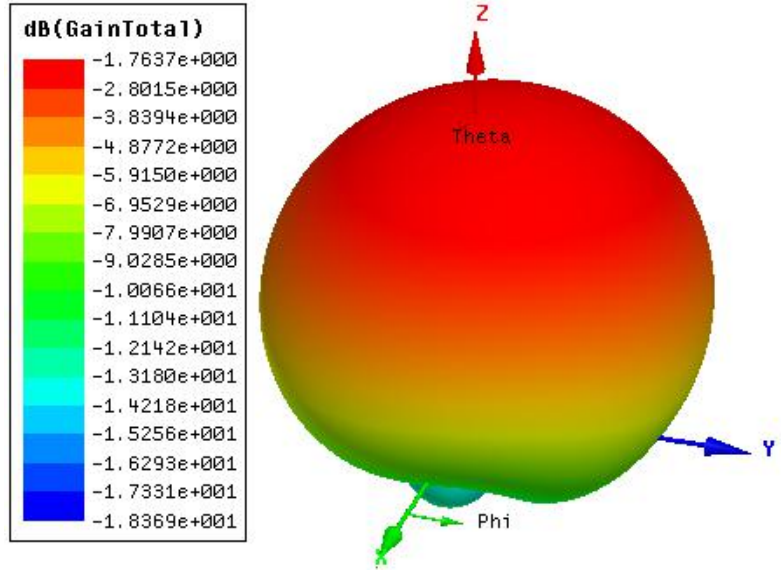

(b)

Fig. 13. Radiation and gain diagram a) 2D, b) 3D.

For the antenna with resonator in position D (Fig. 5e), Fig. 14 shows in the simulation the frequencies of $2.18 \mathrm{GHz}, 2.49 \mathrm{GHz}, 3.21 \mathrm{GHz}, 4.46 \mathrm{GHz}$ and $\mathrm{RL}$ of $-7.97 \mathrm{~dB},-36.26 \mathrm{~dB},-21.44 \mathrm{~dB}$, -16.70. For measurement, they have frequencies of $2.1 \mathrm{GHz}, 2.57 \mathrm{GHz}, 3.18 \mathrm{GHz}$ and RL of $-7.41 \mathrm{~dB}$, $-10.57 \mathrm{~dB},-24.65 \mathrm{~dB}$. Still, both results show close results and good agreement. Fig. 15 shows the E and $\mathrm{H}$ plane of the radiation diagram and the gain. 


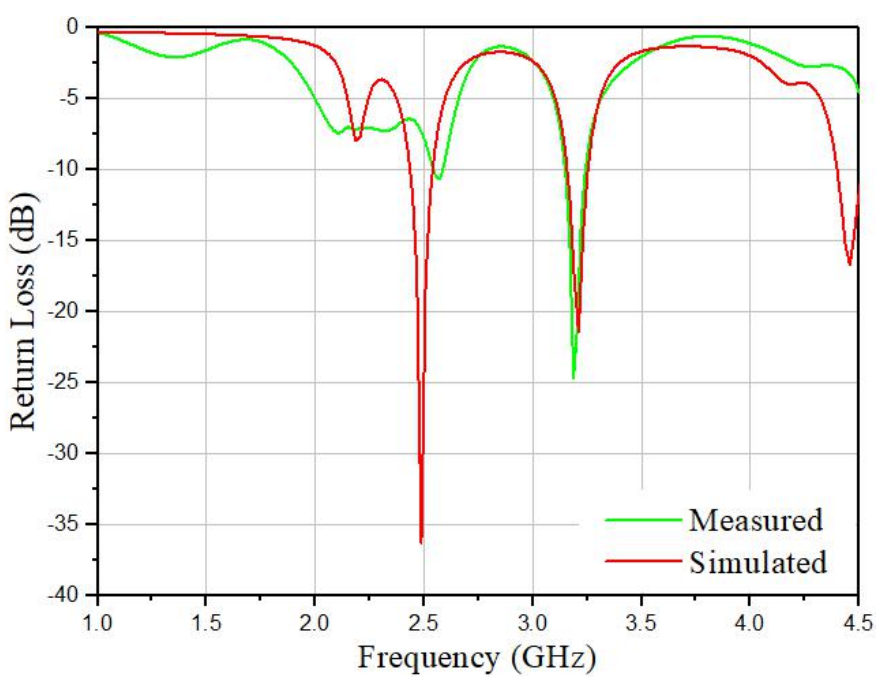

Fig. 14. Return loss to position D.

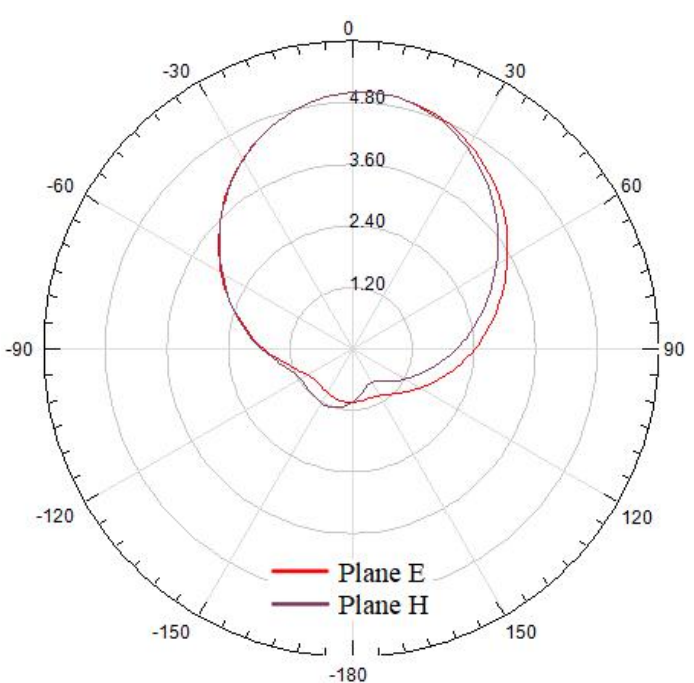

(a)

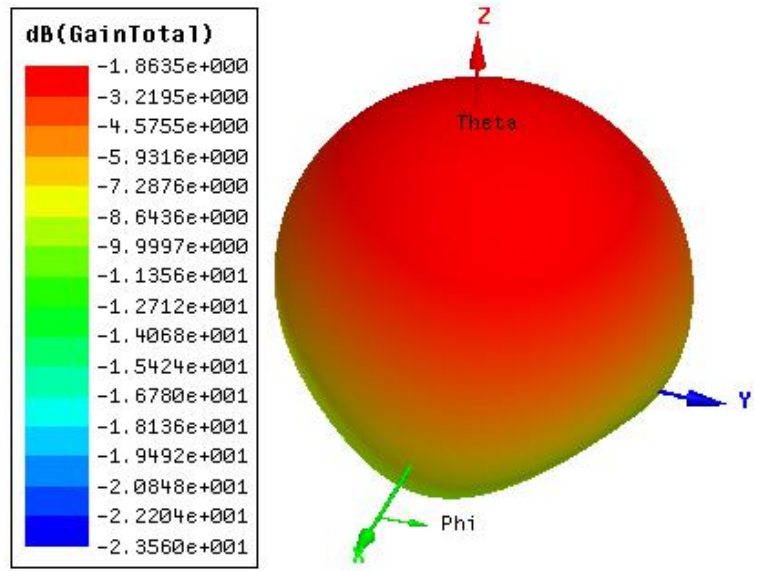

(b)

Fig. 15. Radiation and gain diagram a) 2D, b) 3D.

Analyzing the radiation diagrams, it is noticed that the antenna without resonator and the antennas with resonator in position $\mathrm{B}, \mathrm{C}$ and $\mathrm{D}$, present results with a broadside radiation pattern, that is, all the power is radiated towards the vector normal to the plane of the antenna patch, while the antenna with the resonator in position A, presents directivity distributed in the antenna plane. Furthermore, it is shown that the best gains are related to the resonator positioned in the direction $\pm \widehat{\chi}$, that is, aligned with the supply line in position B and position A, when compared to the antenna without resonator, where currents are important so that the resonator element presents a better response. From table IV, the simulated results of the gains of the antennas, prove the optimization for the positioning of the resonator in the direction $\pm \widehat{X}$. 
TABLE IV. TOTAL ANTENNAS GAIN

\begin{tabular}{cccccc}
\hline \multirow{2}{*}{ Antenna } & $\begin{array}{c}\text { Fig. 3 } \\
\text { Without resonator }\end{array}$ & $\begin{array}{c}\text { Fig. 4a } \\
\text { Position A }\end{array}$ & $\begin{array}{c}\text { Fig. 4b } \\
\text { Position B }\end{array}$ & $\begin{array}{c}\text { Fig. 4c } \\
\text { Position C }\end{array}$ & $\begin{array}{c}\text { Fig. 4d } \\
\text { Position D }\end{array}$ \\
\hline Gain (dB) & -0.7081 & -4.8135 & -15.3570 & -1.7635 & -1.8635 \\
\hline
\end{tabular}

Fig. 16 shows the Chart of the Smith chart for the normalized impedance values of the studied antennas. Based on the simulations, we obtained: Antenna without metamerial $\left(m_{l}=51.82-\mathrm{j} 14.65\right) \Omega$; Antennas with metamaterial: Position A $\left(m_{2}=15.16-\mathrm{j} 12.50\right) \Omega$, position B $\left(m_{3}=41.34-\mathrm{j} 1.41\right) \Omega$, position $\mathrm{C}\left(m_{4}=56.18+\mathrm{j} 1.38\right) \Omega$ and position $\mathrm{D}\left(m_{5}=48.03-\mathrm{j} 0.35\right) \Omega$. It was observed that in position $\mathrm{B}$ and position $\mathrm{D}$ have the best responses in relation to the impedance matching. In addition, a simulation was performed for the surface current density of the antennas with and without metamaterial, according to resonance frequencies for each antenna, as shown in Fig. 17.

To validate the performance of the resonator and its positions in the antenna patch, Table V briefly shows a comparison between works presented in the literature, according to the frequency of operation, type of resonator and bandwidth. It was found that the proposed work presented greater bandwidth for position A with respect to the positions of the CSRR in the patch, compared to the antenna without MTM. In addition, according to Table V, it is observed that the insertion of MTM cells characterizes multiband operation.

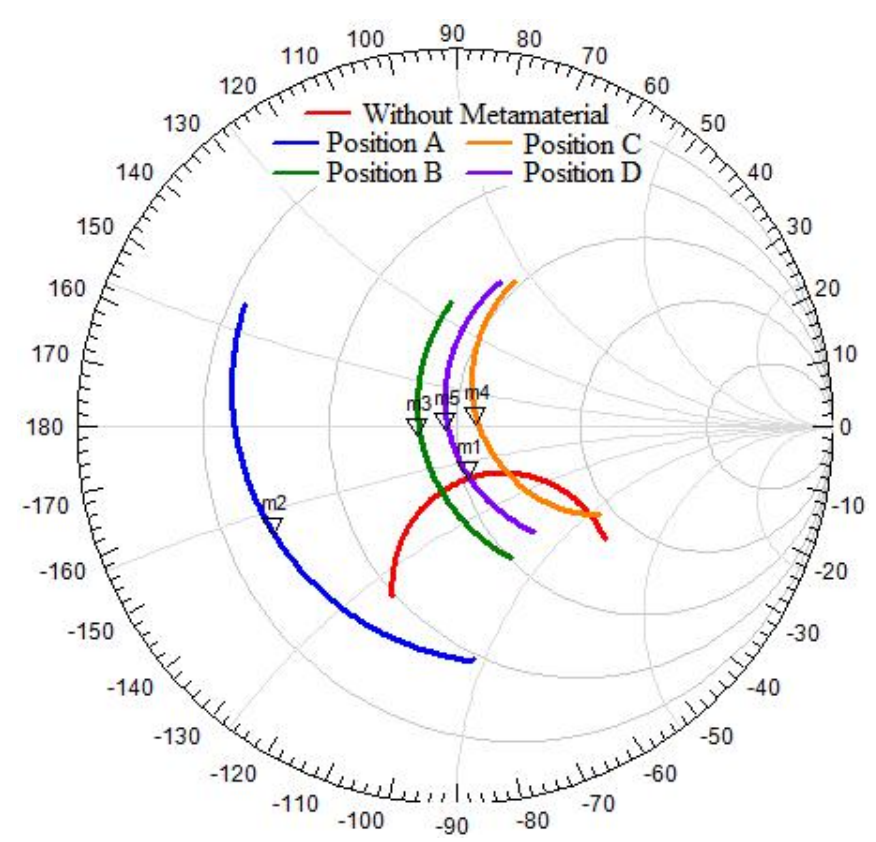

Fig. 16. Smith chart of antennas without and with metamaterial. 


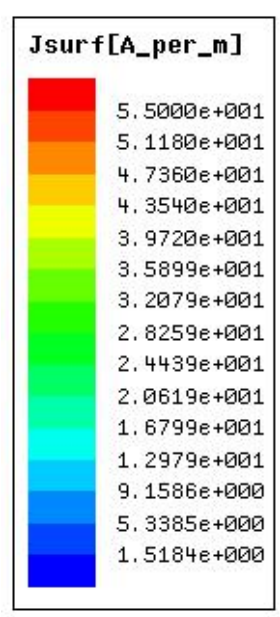

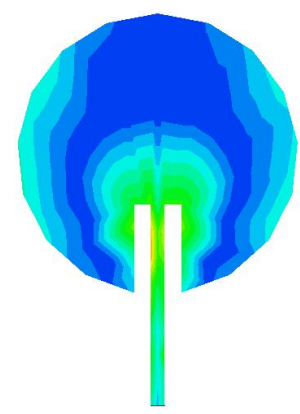

(a)

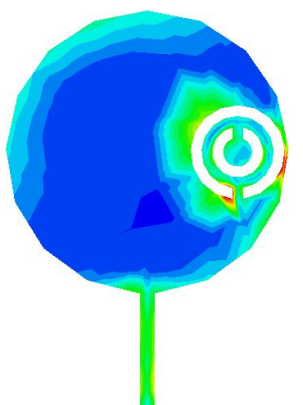

(d)

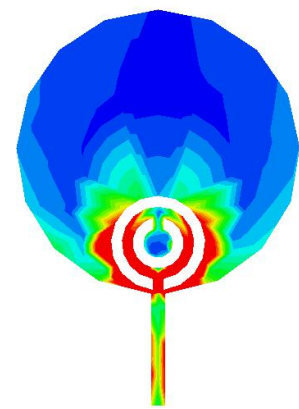

(b)

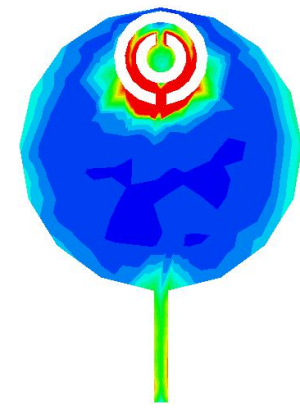

(c)

Fig. 17. Simulated results of surface current density distribution for the antennas a) Without resonator, b) Position A, c) Position B, d) Position C, e) Position D.

TABLE V. COMPARISON BETWEEN ARTICLES WITH RESONATOR IMMERSED IN THE ANTENNA PATCH

\begin{tabular}{cccc}
\hline $\begin{array}{c}\text { Reference } \\
\text { number }\end{array}$ & $\begin{array}{c}\text { Operating frequency } \\
\text { (GHz) }\end{array}$ & $\begin{array}{c}\text { Metamaterial } \\
\text { Resonator }\end{array}$ & $\begin{array}{c}\text { Bandwidth } \\
\mathbf{( \% )}\end{array}$ \\
\hline$[4]$ & $2.45 ; 5.8$ & Fractal Hilbert & 122.58 \\
\hline$[6]$ & 3.07 to 19.91 & Circular SRR & 146,56 \\
\hline$[7]$ & 3.14 to $3.35 ;$ & & \\
& 5.67 to $6.3 ;$ & Square CSRR & $6.5 ; 10.52 ; 22.5$ \\
\hline$[15]$ & 7.58 to 9.5 & & $6.86 ; 5.01 ; 9.16 ;$ \\
\hline$[16]$ & $2.28 ; 2.65 ; 4.8 ;$ & Square RCSRR & $5.38 ; 5.42$ \\
\hline$[17]$ & $5.89 ; 8.73$ & Square SRR & 31.37 \\
\hline$[18]$ & $5.2 ; 5.8$ & Hexagonal CSRRs & 2.5 \\
\hline$[19]$ & 2.1 & Circular CSRR & 131.81 \\
\hline$[20]$ & 4.49 to 21.85 & Square MSRR & $7 ; 12$ \\
\hline$[21]$ & $2.78 ; 5.88$ & Circular CSRR & $41.58 ; 43.96$ \\
\hline & $6.81 ; 10.65$ & Circular CSRR & 75.42 \\
\hline Proposed & 7.17 & Circular CSRR (position A) & 24.75 \\
\cline { 2 - 5 } work & 2.25 & Circular CSRR (position B) & $4.98 ; 2.04$ \\
\hline & $2.55 ; 3.19$ & Circular CSRR (position C) & $0.78 ; 3.15$ \\
\hline & $2.57 ; 3.18$ & Circular CSRR (position D) & $0.39 ; 2.51$ \\
\hline
\end{tabular}




\section{CONCLUSION}

In this article, a simple and easy to manufacture resonator geometry was proposed to be applied to the patch of a circular antenna, in different positions. Parametric analyzes were performed using the ANSYS HFSS ${ }^{\circledR}$ software, then prototypes were manufactured and measured to validate the results.

Therefore, it was observed that the antenna designs met equation (2) for an approximate calculation of the circular patch, as well as the Federal Communication Commission (FCC) for the return loss below $-10 \mathrm{~dB}$, which can be produced commercially.

In addition, the antenna with resonator in position $A$ and aligned in the direction $\pm \widehat{x}$ with the power line, showed a better performance, that is, depending on the position of the CSRR in the patch, it can considerably increase the gain, change the width of band, but also to change the operating frequency and radiation of the antenna. It was also found that the use of the resonator resulted in better gains when compared to the antenna without resonator.

Thus, this work showed that the results proved the simplicity of the resonator and the application of an approximation calculation for the circular antenna patch, made possible a good agreement between the results.

\section{ACKNOWLEDGMENT}

The authors wish to acknowledge the UFRN/PPGEEC, UFERSA/CMPF and UFERSA/PPGEE for the commercial software licence ( $\mathrm{n}^{\circ}$ 1058710). This study was financed in part by the Coordenação de Aperfeiçoamento de Pessoal de Nível Superior - Brasil (CAPES) - Finance Code 001.

\section{REFERENCES}

[1] C. A. Ballanis, “Antenna Theory: Analysis and Design,” New Jersey, 2005.

[2] T. A. Elwi, "Novel UWB printed metamaterial microstrip antenna based organic substrate for RF-energy harvesting applications', Intern. Journal of Elect.and Commun. , vol.101, pp. 44-53, 2019.

[3] A. W. Saadh and T. Ali, "A compact coaxial fed metamaterial antenna for wireless applications", Journal of Instrumentation, vol. 14, no. 6, pp. P06025, 2019.

[4] D. C. Corrêa, U. C. Resende, F. S. Bicalho and Y. S. Gonçalves, "Design, optimization and experimental evalution of a F-shaped Multiband metamaterial antenna," Journal of Microw. Opt. and Electrom. Applic., vol. 17, pp. 590-603, 2018.

[5] V. G. Veselago, "The electrodynamics of substances with simultaneously negative values of E and mi," Soviet Physics Uspekhi, vol. 10, pp. 509-514, 1968.

[6] M. M. Islam, M. T. Islam, M. Samsuzzaman and M. R. I. Faruque, "Compact metamaterial antenna for UWB applications," Electronics Letters, vol. 51, pp. 1222-1224, 2015.

[7] R. Salhi, M. Labidi and F. Choubani, "A design of multi-band antenna based on active metamaterials," Optical Materials, vol. 84, pp. 307-311, 2018.

[8] S. Robinson, "Design and Analysis of split ring resonator based microstrip patch antenna for X-band applications," Journal on Microelectronics, vol. 04, 2019.

[9] N. I. Zheludev and Y. S. Kivshar, "From metamaterials to metadevices," Nature Materials, vol. 11, no 11, p.917, 2012.

[10] A. T. Devapriya and S. Robinson, "Investigation on metamaterial antenna for terahertz applications," Journal of Microw. Opt. and Electrom. Applic., vol. 18, no 3, pp. 377-389, 2019.

[11] D. A. Ketzaki and T. V. Yioultsis, "Metamaterial-based design of planar compact MIMO monopoles," IEEE Trans. on Antennas and Prop., vol. 61, pp. 2758-2766, May 2013.

[12] S. Naoui, L. Latrach and A. Gharsallah, "Metamaterials microstrip patch antenna for wireless communication RFID technology," Microw. Opl. Technol. Lett., vol. 57, pp. 1060-1066, 2015.

[13] J. G. D. Oliveira, E. N. M. G. Pinto, V. P. S. Neto and A. G. D’Assunção, ”CSRR-Based microwave sensor for dielectric materials characterization applied to soil water content determination', Sensors, vol. 20, pp. 1-16, 2020.

[14] T. Ali, A. W. M. Saadh, R. C. Biradar, J. Anguera and A. Andújar, "A miniaturized metamaterial slot antenna for wireless applications," Int. Journal Electronics Commun., vol. 82, pp. 368-382, 2017.

[15] S. Roy, K. L Baishnab and U. Chakraborty, "Beam focusing compact wideband antenna loaded with mu-negative metamaterial for wireless LAN application”, Progress In Electrom. Research C, vol. 83, pp. 33-44, 2018. 
[16] D. C. Ochoa, D. E. Senior, F. Lopes and E. R. Vera, "Performance analysis of a microstrip patch antenna loaded with array of metamaterial resonators," Intern. Symposium on Ant. and Propagation (APSURSI) 2016.

[17] S. S. Islam, T. Alam, M. R. I. Faruque and M. T. Islam, "Design and analysis of a complementary split ring resonator (CSRR) metamaterial based antenna for wideband application," Science and Engineering of Composite Materials, vol. 24, pp. 573-580, 2017.

[18] N. T. Selvi, R. Pandeeswari and P.T. Selvan, "An inset-fed rectangular microstrip patch antenna with multiple split ring resonator loading for WLAN and RF-ID application”, Progress In Electrom. Research C, vol. 81, pp. 41-52, 2018.

[19] I. B. T. da Silva, H. D. de Andrade, J. L. da Silva, H. C. C. Fernandes and J. P. P. Pereira, "Design of microstrip patch antenna with complementary split ring resonator device for wideband systems application," Microw. Opl. Technol. Lett., vol. 57, pp. 1326-1330, 2015.

[20] I. B. T. da Silva, H. D. de Andrade, J. L. da Silva and H. C. C. Fernandes, "Influence of complementary split ring resonator dimensions in ultra wideband microstrip patch antenna," Proceedings of the 2015 IEEE 9th European Conference on Antennas and Propagation (EuCAP), vol. 57, Lisbon, Portugal, pp. 1-5, 2015.

[21] A. Salim and S. Lim, "Review of recent metamaterial microfluidic sensors," Sensors, vol. 18, pp. 1-25, 2018.

[22] M. A. Matin, and A. I. Sayeed,"A design rule for inset-fed rectangular microstrip patch antenna",WSEAS Transactions on Communications, vol. 9, 2010.

[23] O. P. Lavor, Bi anisotropy in rectangular microstrip antennas and modified circular structures (in Portuguese), Ph.D. Thesis, Federal University of Rio Grande do Norte, Natal, RN, Brazil, 2015. 